\title{
Exploring the Catalytic Activity of Zirconia, Zirconia Supported Metals and Metal Oxides for Oxidation of Phenol
}

\author{
Mohammad Sadiq ${ }^{1,2 *}$, Mohammad Ilyas ${ }^{2}$ \\ ${ }^{1}$ Department of Chemistry, University of Malakand, Chakdara, Dir (Lower), Khyber Pakhtunkhwa, Pakistan \\ ${ }^{2}$ National Centre of Excellence in Physical Chemistry, University of Peshawar, Peshawar, Pakistan \\ Email: *mohammad_sadiq26@yahoo.com, *sadiq@uom.edu.pk
}

Received May 2, 2012; revised June 18, 2012; accepted July 10, 2012

\begin{abstract}
Catalytic oxidation/degradation of phenol with molecular oxygen in aqueous medium by Zirconia, zirconia supported metals and metal oxides at low temperature were studied in a three necked batch reactor. The catalysts prepared were characterized by modern techniques like XRD, SEM and EDX. The activities of different catalysts for the oxidation of phenol in aqueous medium were found to be in the order; $\mathrm{Pt}-\mathrm{Pd} / \mathrm{ZrO} \mathrm{Z}_{2}>\mathrm{Bi}-\mathrm{Pt} / \mathrm{ZrO}_{2}>\mathrm{Bi}-\mathrm{Pd} / \mathrm{ZrO} \mathrm{Z}_{2}>\mathrm{Pt} / \mathrm{ZrO} \mathrm{C}_{2}>\mathrm{Pd} / \mathrm{ZrO}{ }_{2}>$ $\mathrm{Cu} / \mathrm{ZrO}_{2}>\mathrm{Mn} / \mathrm{ZrO}_{2}>\mathrm{Bi} / \mathrm{ZrO}_{2}$. The enhanced catalytic activity of $\mathrm{Bi}-\mathrm{Pt} / \mathrm{ZrO}_{2}$ is attributed to $\mathrm{Bi}$ which in contact with $\mathrm{Pt}$ particles promotes its catalytic activity. In short, catalytic oxidation was found to be an effective tool, for the removal of phenol, from industrial waste water.
\end{abstract}

Keywords: Oxidation; Phenol; Bismuth; Platinum; Zirconia

\section{Introduction}

Undesired phenol wastes are produced by many industries including the chemicals, plastics and resins, coke, steel, and petroleum industries. Phenol is one of the EPA's Priority Pollutants. Under Section 313 of the Emergency Planning and Community Right to Know Act of 1986 (EPCRA), release of more than one pound of phenol into the air, water and land must be reported, annually, and entered into the Toxic Release Inventory (TRI). Phenol has a high oxygen demand and can thus readily deplete oxygen in the receiving water, with detrimental effects on those organisms that extract dissolved oxygen from water, for their metabolism. It is also well known that even low phenol level, in the parts per billion ranges, imparts disagreeable taste and odor to water. Therefore, it is necessary to eliminate maximum possible quantity of phenol from the wastewater before it is being discharged. Phenol may be treated by chemical oxidation, bio-oxidation and adsorption. Chemical oxidation such as with hydrogen peroxide or chlorine dioxide has a low capital but a high operating cost. Bio-oxidation has a high capital and a low operating cost. Adsorption has both high capital and operating costs. The appropriateness of any one of these methods depends on a combination of factors; the most important of which are the phe-

"Corresponding author. nol concentration and any other chemical pollutant that may be present in the wastewater. Depending on these variables, a single or a combination of treatments may be used. Currently, phenol removal is accomplished with chemical oxidants, the most commonly used, being chlorine dioxide, hydrogen peroxide and potassium permanganate. Heterogeneous catalytic oxidation, of dissolved organic compounds, is a potential mean for the remediation of contaminated ground and surface waters, industrial effluents and other wastewater streams. The ability to carry out the process at substantially milder conditions of temperature and pressure, in comparison to supercritical water oxidation and wet air oxidation, is achieved through the use of an extremely active supported noble metal catalyst. Catalytic Wet Air Oxidation (CWAO) appears as one of the most promising processes but only at elevated conditions of pressure and temperature in the presence of metal oxide and supported metal oxide [1]. Although homogeneous copper catalysts are effective for the wet oxidation of industrial effluents but the removal of toxic catalyst has made the process debatable [2]. Recently, Leitenburg et al. have reported that the activities of mixed-metal oxides such as of $\mathrm{ZrO}_{2}, \mathrm{MnO}_{2}$, or $\mathrm{CuO}$ for the oxidation of acetic acid can be enhanced by adding ceria as a promoter [3]. Imamura et al. have studied the catalytic activities of supported noble metal catalysts for the wet oxidation of phenol and the other model pol- 
lutant compounds. Ruthenium, Platinum and Rhodium supported on $\mathrm{CeO}_{2}$ were found to be more active than a homogeneous copper catalyst [1]. Atwater et al. have shown that several classes of aqueous organic contaminants, can be deeply oxidized, using dissolved oxygen over supported noble metal catalysts (5\% Ru-20\% Pt/C), at a temperature 393 - $433 \mathrm{~K}$ and pressure between 2.3 and 6 atmospheres [4]. Carlo et al. [5] have reported that lanthanum strontium manganites are very active catalysts for the catalytic wet oxidation of phenol. Castro et al. [6] have reported that polymer-supported metal complexes have been used as catalysts for the catalytic wet hydrogen peroxide oxidation of Phenol with high yield; however the unacceptable point was leaching of the metal. In the present work, we explored the effectiveness of zirconia-supported noble metals (Pt and $\mathrm{Pd}$ ) and bismuth promoted zirconia supported noble metals for the oxidation of phenol in aqueous solution.

\section{Experimental}

\subsection{Materials}

$\mathrm{ZrOCl}_{2} \cdot 8 \mathrm{H}_{2} \mathrm{O}$ (Merck, 8917), $\mathrm{NH}_{4} \mathrm{OH}$ (BDH, 27140), $\mathrm{AgNO}_{3}$ (Merck, 1512), $\mathrm{PtCl}_{4}$ (Acros, 19540), Palladium (II) chloride (Scharlau, Pa 0 025), phenol (Acros, 41717), alizarin (Acros, 400480250), Potassium Iodide (BDH, 102123B) and 2, 4-Dinitro phenyl hydrazine (BDH, 100099) were used as received. $\mathrm{H}_{2}(99.999 \%)$ was prepared using hydrogen generator (GCD-300, BAIF). Nitrogen and Oxygen were supplied by BOC Pakistan Ltd. and were further purified by passing through traps (C.R.S.Inc.202268), to remove traces of water and oil. Traces of oxygen from nitrogen gas were removed by using specific oxygen traps (C.R.S.Inc.202223).

\subsection{Catalyst Preparation}

Zirconia was prepared using an aqueous solution of zirconyl chloride [7-9] with a drop wise addition of $\mathrm{NH}_{4} \mathrm{OH}$ for 4 hours (pH: 10 - 12) and continuous stirring all along. The precipitate was washed with triply distilled water for 24 hours, using a Soxhlet's apparatus, until the chloride ion test with $\mathrm{AgNO}_{3}$ was found to be negative. Precipitate was dried at $110^{\circ} \mathrm{C}$ for 24 hours. After drying, it was calcined with programmable heating at a rate of $0.5 \_\mathrm{C} / \mathrm{min}$ to achieve a temperature of $950^{\circ} \mathrm{C}$, which was then maintained, for 4 hours. Nabertherm C-19 programmed control furnace was used for calcination.

\subsection{Metals and Metals Oxides Supported on Zirconia}

Supported Catalysts \{i. $\mathrm{Pt}(2 \mathrm{wt} \%) / \mathrm{ZrO}_{2}$ ii. $\mathrm{Pd}(2 \mathrm{wt} \%) / \mathrm{ZrO}_{2}$ iii. $\mathrm{Pd}(1 \mathrm{wt} \%)$ and $\mathrm{Pt}(1 \mathrm{wt} \%) / \mathrm{ZrO}_{2}$ iv. $\mathrm{Bi}(0.5 \mathrm{wt} \%)$ $\mathrm{Pt}(2 \mathrm{wt} \%) / \mathrm{ZrO}_{2} \quad$ v. $\left.\mathrm{Bi}(0.5 \mathrm{wt} \%) \mathrm{Pd}(2 \mathrm{wt} \%) / \mathrm{ZrO}_{2}\right\} \quad$ were prepared, by incipient wetness technique. For this purpose, calculated amount (wt\%) of the precursor compound $\left(\mathrm{PdCl}_{4}\right.$ or $\left.\mathrm{PtCl}_{4}\right)$ was taken in a crucible and triply distilled water was added to it, to make a paste. Then the required amount of the support $\left(\mathrm{ZrO}_{2}\right)$ was mixed with it. The paste was thoroughly mixed and dried in an oven at $110^{\circ} \mathrm{C}$ for 24 hours and then ground. The catalyst was sieved and 80 - 100 mesh portions were used for further treatment. The ground catalyst was calcined again, at a rate of $0.5^{\circ} \mathrm{C} / \mathrm{min}$, to achieve a temperature of $950^{\circ} \mathrm{C}$, which was then maintained, for 4 hours, followed by a reduction in $\mathrm{H}_{2}$ flow ( $40 \mathrm{~mL} / \mathrm{min}$ ), at $280^{\circ} \mathrm{C}$, for 4 hours. The supported multi-component catalysts, were prepared by successive incipient wetness impregnation of the support with bismuth and precious metals, followed by drying and calcination. Bismuth was first added to zirconia support by the incipient wetness impregnation procedure. After drying and calcination, Bi/zirconia was then impregnated with the active metals such as Pd or Pt. The final sample was then passed through the same drying and calcination procedures. The metal loading of the catalyst was calculated from the weight of chemicals used for impregnation.

\subsection{Morphological Study}

XRD analyses were performed using a JEOL (JDX-3532) diffractometer with $\mathrm{CuK}_{a}$ radiation $\left(k_{\alpha}=1.5406 \AA\right.$ ) operated at $40 \mathrm{kV}$ and $20 \mathrm{~mA}$. SEM and EDX measurements were performed using scanning electron microscope of Joel 50 H super prob 733.

\subsection{Oxidation of Phenol}

Oxidation of phenol in aqueous medium was carried out, in a magnetically stirred, Pyrex glass double walled flat bottom three-necked batch reactor, equipped with a reflux condenser and a mercury thermometer. The reaction temperature was maintained, by using water circulator (WiseCircu, Fuzzy control system). A predetermined quantity of the substrate solution $(20 \mathrm{~mL})$ was taken in the reactor and a desired amount $(0.2 \mathrm{~g})$ of catalyst was added to it. The reaction during heating period was negligible since no direct contact existed between oxygen and the catalyst. $\mathrm{O}_{2}$ and $\mathrm{N}_{2}$ gases at atmospheric pressure were allowed to pass through the reaction mixture at a flow rate of $40 \mathrm{~mL} / \mathrm{min}$ at a fixed temperature. When the temperature and pressure reached the desired values, the stirrer was set at $900 \mathrm{rpm}$ and turned on. The reaction mixture was analyzed by GC (Clarus 500, Perkin Elmer equipped with (FID and TCD) and capillary column (Elite-5, L 30 m, ID 0.25, DF 0.25), UV spectrophotometer (UV-160, Shamidzo, Japan) and COD was measured by the potassium dichromate method [10]. 


\section{Results and Discussion}

\subsection{Characterization of Catalyst}

X-ray diffraction pattern of the sample, reported in Figure 1, confirms the monoclinic structure of zirconia. The major peaks indicating the monoclinic structure of zirconia appear at $2 \theta=28.18^{\circ}$ and $31.38^{\circ}$ while no peak, characteristic for tetragonal phase $\left(2 \theta=30.94^{\circ}\right)$, appears suggesting that zirconia is purely present in monoclinic phase. The reflections were observed for Pd at $2 \theta=40.4^{\circ}$ and $46.9^{\circ}$ and for Pt at $2 \theta=39.79^{\circ}$ and $46.28^{\circ}$ respectively. For $\mathrm{Bi}_{2} \mathrm{O}_{3}$, the peaks appear at $2 \theta=27.7^{\circ}, 30.5^{\circ}$, $33^{\circ}, 42.4^{\circ}$ and $47.2^{\circ}$ while for $\mathrm{MnO}_{2}$ major peak appears at $2 \theta=26.1^{\circ}, 28.9^{\circ}$. In all these catalysts zirconia maintains its monoclinic phase. SEM micrographs of fresh samples, reported in Figure 2, show the homogeneity of the crystal size of monoclinic zirconia. The micrographs of $\mathrm{Pt} / \mathrm{ZrO}{ }_{2}, \mathrm{Pd} / \mathrm{ZrO}{ }_{2}, \mathrm{Pt}-\mathrm{Pd} / \mathrm{ZrO}_{2}$ and $\mathrm{Bi}_{2} \mathrm{O}_{3} / \mathrm{ZrO}_{2}$ reveal that the active metals are well dispersed on the support. Figure 3 shows the EDX analysis results for fresh and used $\mathrm{Bi}(0.5 \mathrm{wt} \%) \quad \mathrm{Pt}(2 \mathrm{wt} \%) / \mathrm{ZrO}_{2}$ and $\mathrm{Bi}(0.5 \mathrm{wt} \%)$ $\mathrm{Pd}(2 \mathrm{wt} \%) / \mathrm{ZrO}_{2}$ samples. The results show the presence of carbon in the used samples which probably comes from the total oxidation of the organic substrate. Many researcher have reported the presence of chlorine and carbon in the EDX analysis of freshly prepared samples $[7,8]$, suggesting that chlorine comes form the matrix of zirconia while carbon from ethylene diamine. In our case, we did not use ethylene diamine and no carbon was observed, in the EDX analysis of fresh samples. Also, no chlorine was found in our studies, because of careful washing of the samples.

\subsection{Catalytic oxidation of phenol}

Oxidation of phenol was significantly higher over (2 wt\%) $\mathrm{Pt} / \mathrm{ZrO}_{2}$ catalyst. Combination of (1wt\%) Pd and (1wt\%) Pt on $\mathrm{ZrO}_{2}$ gave an activity, comparatively higher than that of the (2wt\%) $\mathrm{Pd} / \mathrm{ZrO}_{2}$ or $(2 \mathrm{wt} \%)$ $\mathrm{Pt} / \mathrm{ZrO}_{2}$ catalysts. Adding $0.5 \%$ Bismuth significantly increased the activity of the (2wt\%) $\mathrm{Pt} / \mathrm{ZrO}_{2}$, which shows promising activity for destructive oxidation of organic pollutants in the effluents at $333 \mathrm{~K}$ and $101 \mathrm{kPa}$ in the liquid phase. Addition of $0.5 \%$ Bismuth however, inhibited the activity of the $\mathrm{ZrO}_{2}$ supported (2wt\%) Pd catalyst.

\subsection{Effects of Different Parameters}

Alterations in different parameters of the reaction have significant effect on the catalytic oxidation of phenol, in aqueous medium. In comparison to homogeneous catalytic oxidation of phenol, heterogeneous catalytic oxidation appears to be less sensitive to $\mathrm{pH}$ and more efficient [9]. The conversion of the phenol with time is reported in

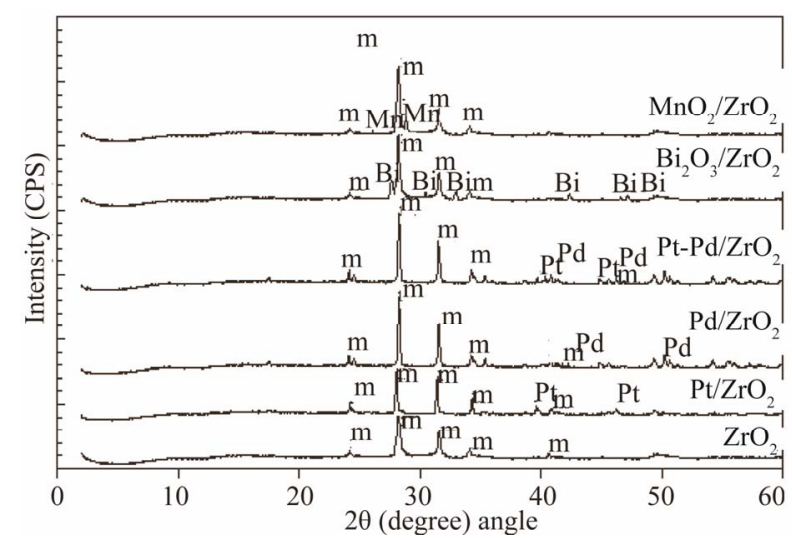

Figure 1. XRD of different catalysts (m: peaks for monoclinic $\mathrm{ZrO}_{2}$ ).

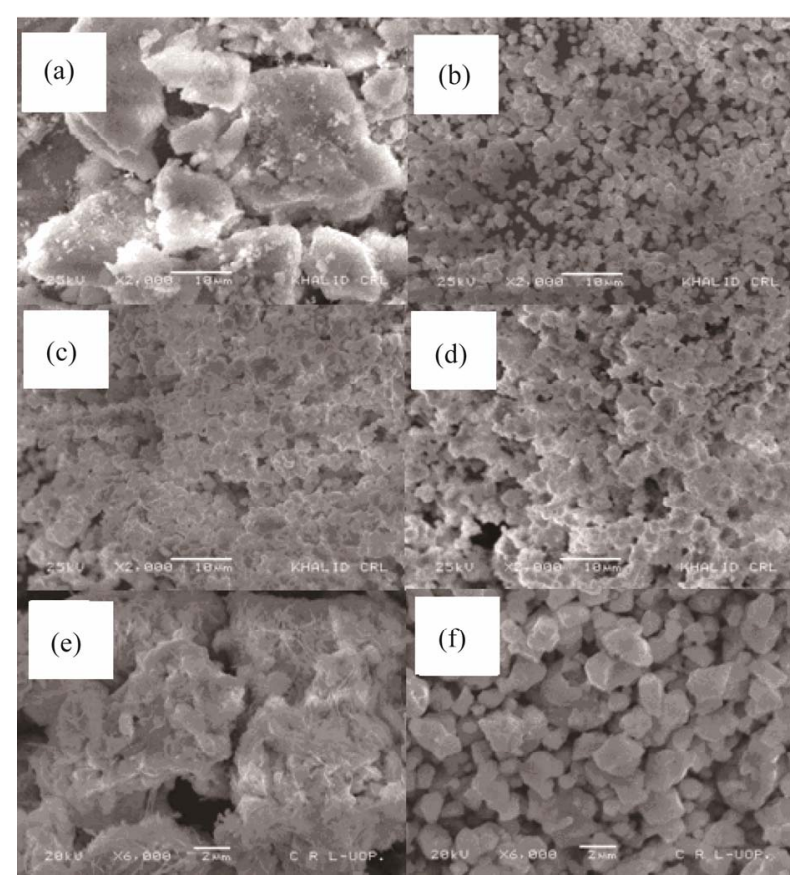

Figure 2. SEM of different catalyst; (a) $\mathrm{ZrO}_{2}$; (b) $\mathrm{Pt} / \mathrm{ZrO}_{2}$; (c) $\mathrm{Pd} / \mathrm{ZrO}_{2}$; (d) $\mathrm{Pt}-\mathrm{Pd} / \mathrm{ZrO}_{2}$; (e) $\mathrm{B}_{\mathrm{i} 2} \mathrm{O}_{3}$; (f) $\mathrm{B}_{\mathrm{i} 2} \mathrm{O}_{3} / \mathrm{ZrO}_{2}$.

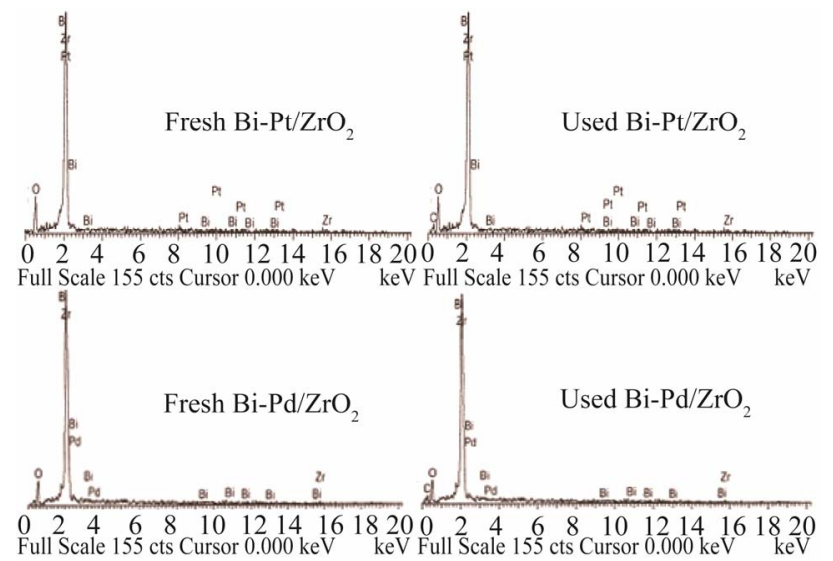

Figure 3. EDX of different catalysts (fresh and used). 
Figure 4 for Bi promoted zirconia supported platinum catalyst. In the blank experiment, no conversion is obtained after 3 hours while nearly total conversion is achieved with $\mathrm{Bi}-\mathrm{Pt} / \mathrm{ZrO}_{2}$ in $3 \mathrm{~h}$. Bismuth promoted zirconia-supported platinum catalyst shows a very good specific activity for phenol conversion (Figure 4). Leaching of the catalyst was checked and the reaction was found purely heterogeneous. The activities of different catalysts were found in the order $\mathrm{Pt}-\mathrm{Pd} / \mathrm{ZrO}_{2}>$ $\mathrm{Bi}-\mathrm{Pt} / \mathrm{ZrO}_{2}>\mathrm{Bi}-\mathrm{Pd} / \mathrm{ZrO}_{2}>\mathrm{Pt} / \mathrm{ZrO}_{2}>\mathrm{Pd} / \mathrm{ZrO}_{2}>\mathrm{Cu} / \mathrm{ZrO}_{2}>$ $\mathrm{Mn} / \mathrm{ZrO}_{2}>\mathrm{Bi} / \mathrm{ZrO}_{2}$. Bi-Pt/ZrO 2 is the most active catalyst which suggests that $\mathrm{Bi}$ in contact with $\mathrm{Pt}$ particles promotes metal activity as shown in Figure 5. However, although very high conversions can be obtained ( 91\%), total mineralization of phenol is never observed. It is reported that organic intermediates are still present in the solution [11]. Platinum and palladium loading influence the catalytic activity. An increase in Pt loading improves the activity significantly and the conversion of phenol increases linearly with increase in Pt loading. In contrast to platinum, an increase in Pd loading improves the activity not very significantly [12]. The influence of bismuth on catalytic activities of $\mathrm{Pt} / \mathrm{ZrO}_{2}$ catalysts is reported in

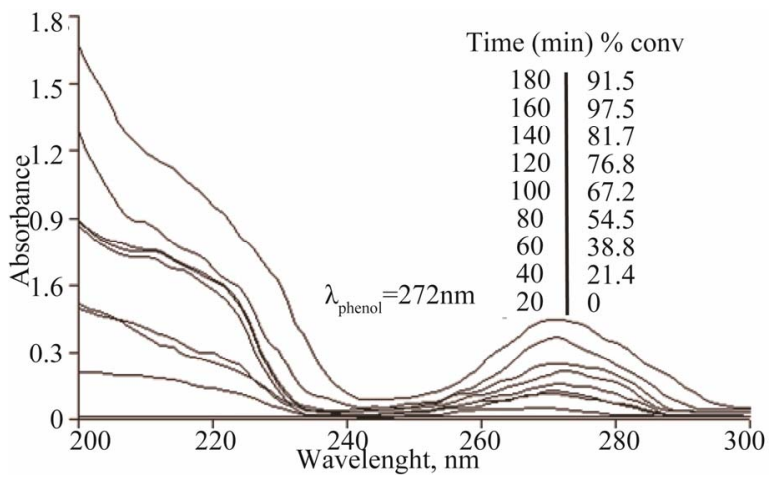

Figure 4. Time profile study. Reaction Conditions: Temp; $333 \mathrm{~K}$, Cat; $0.2 \mathrm{~g}\left\{\mathrm{Bi}(0.5 \mathrm{wt} \%) \mathrm{Pt}(2 \mathrm{wt} \%) / \mathrm{ZrO}_{2}\right\}$, substrate solution; $20 \mathrm{~mL}$ (Conc; $10 \mathrm{~g} \cdot \mathrm{dm}^{-3}$ ) of phenol in water, $\mathrm{pO}_{2}$; 760 Torr and agitation; $900 \mathrm{rpm}$.

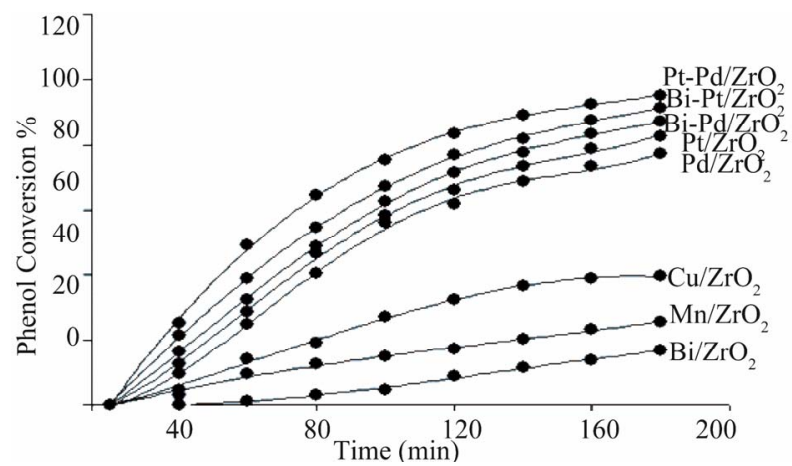

Figure 5. Comparison of different catalysts. Reaction Conditions: Temp; $333 \mathrm{~K}$, Cat; 0.2 g, substrate solution; $20 \mathrm{~mL}$ $\left(10 \mathrm{~g} \cdot \mathrm{dm}^{-3}\right)$ of phenol in water, $\mathrm{pO}_{2} ; 760$ Torr and agitation; $900 \mathrm{rpm}$.
Figure 6. Adding $0.5 \mathrm{wt} \% \mathrm{Bi}$ improves the activity of $\mathrm{Pt} / \mathrm{ZrO}_{2}$ catalyst, with a ( 1 and $2 \mathrm{wt} \% \mathrm{Pt}$ ) loading. In contrast to supported Pt catalyst, the activity of supported Pd catalyst with a (1wt\%) Pd loading, decreases, by the addition of $\mathrm{Bi}$ to zirconia. The profound inhibiting effect was observed with a $\mathrm{Bi}$ loading of $0.5 \mathrm{wt} \%(2 \mathrm{wt} \%)$ $\mathrm{Pd} / \mathrm{ZrO}_{2}$. Bi as an active metal supported on zirconia has very poor activity while as a promoter shows remarkable activity. High catalytic activity was obtained for reduced catalysts as shown in Figure 7. $\mathrm{Pt} / \mathrm{ZrO}_{2}$ was more reactive than $\mathrm{PtO} / \mathrm{ZrO}_{2}$. Similarly reduced $\mathrm{Pd} / \mathrm{ZrO}_{2}$ were found to be more reactive than the unreduced Pd supported on zirconia. This increase in catalytic activity with reduction is attributed to the transformation of a fraction of tetragonal zirconia into monoclinic phase. Furthermore, monoclinic zirconia is more active for oxidation than tetragonal zirconia is [13,14]. Figure 8 reveals that with increase in temperature, the conversion of phenol increases, reaching a maximum conversion at $333 \mathrm{~K}$. The apparent activation energy is $\sim 68.3 \mathrm{~kJ} / \mathrm{mol}$. The value of activation energy in the present case where the agitation speed was kept 1200rpm shows that the reaction is probably free of mass transfer limitation [15].

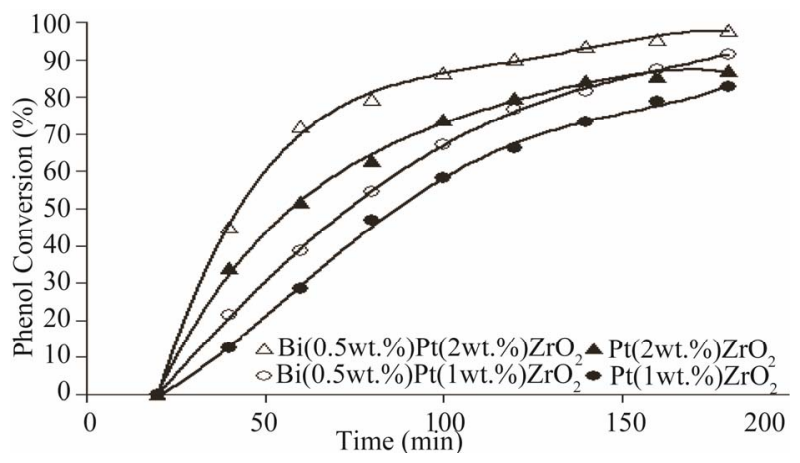

Figure 6. Effect of promoter $\mathrm{Bi}(0.5 \mathrm{wt} \%)$ on catalytic activity of $\mathrm{Pt}(2 \mathrm{wt} \%) / \mathrm{ZrO}_{2}$ and $\mathrm{Pt}(1 \mathrm{wt} \%) / \mathrm{ZrO}_{2}$. Reaction Conditions: Temp $333 \mathrm{~K}$, Cat $0.2 \mathrm{~g}$, substrate solution $20 \mathrm{ml}$ (conc; $10 \mathrm{~g} \cdot \mathrm{dm}^{-3}$ ) of phenol in water, $\mathrm{pO}_{2} 760$ Torr and agitation $900 \mathrm{rpm}$.

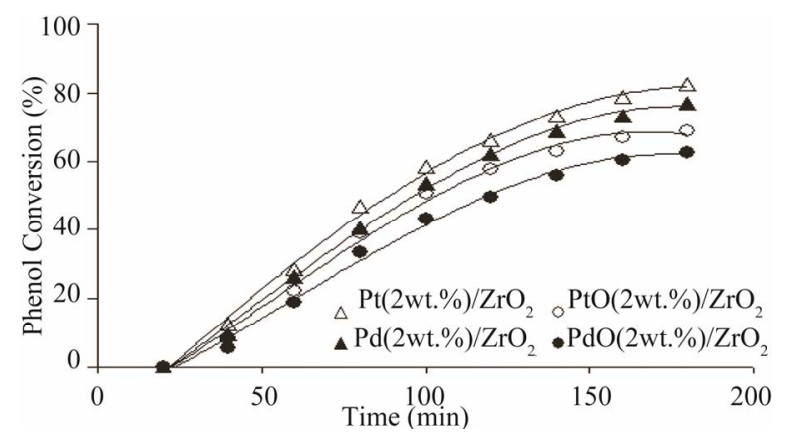

Figure 7. Comparison of reduced $\left(\mathrm{H}_{2}\right.$ flow at $280^{\circ} \mathrm{C}$ for 4 hours) and unreduced catalysts. Reaction Conditions: Temp $333 \mathrm{~K}$, Cat $0.2 \mathrm{~g}$, substrate solution $20 \mathrm{~mL}$ (conc; $10 \mathrm{~g} \cdot \mathrm{dm}^{-3}$ ) of phenol in water, $\mathrm{pO}_{2} 760$ Torr and agitation $900 \mathrm{rpm}$. 


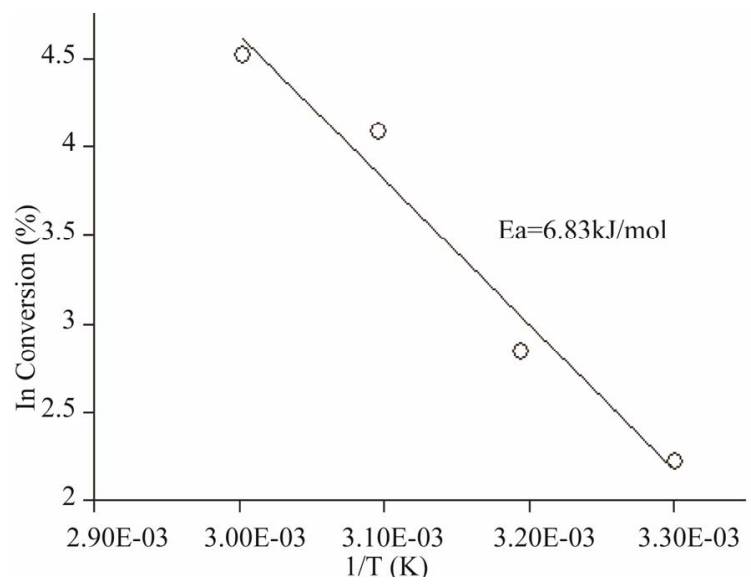

Figure 8. Effect of temperature on the conversion of phenol. Reaction condition: Temp 303 - 333K, Cat; 0.2 g Bi(0.5wt\%) $\mathrm{Pt}(2 \mathrm{wt} \%) / \mathrm{ZrO}_{2}$, substrate $20 \mathrm{~mL}$ (conc; $10 \mathrm{~g} \cdot \mathrm{dm}^{-3}$ ), $\mathrm{pO}_{2} 760$ Torr and agitation $900 \mathrm{rpm}$.

\section{Conclusion}

Both bismuth promoted $\mathrm{Pt} / \mathrm{ZrO}_{2}$ and $\mathrm{Pd} / \mathrm{ZrO}_{2}$ catalysts are very promising for the destructive oxidation of the organic pollutants in the industrial effluents. Addition of $\mathrm{Bi}$ improves the activity of $\mathrm{Pt} / \mathrm{ZrO}_{2}$ catalysts but inhibits the activity of $\mathrm{Pd} / \mathrm{ZrO}_{2}$ catalyst at a high loading of Pd. Optimal conditions for better catalytic activity are: temp $333 \mathrm{~K}$, wt of catalyst $0.2 \mathrm{~g}$, agitation $900 \mathrm{rpm}, \mathrm{pO}_{2} 101 \mathrm{kPa}$ and time $180 \mathrm{~min}$. Among the emerging alternative processes, the supported noble metals catalytic oxidation was found to be the most effective for the treatment of several pollutants like phenols, at milder temperatures and pressures.

\section{REFERENCES}

[1] S. Imamura, "Catalytic and Noncatalytic Wet Oxidation," Industrial \& Engineering Chemistry Research, Vol. 38, No. 5, 1999, pp. 1743-1753. doi:10.1021/ie9805761

[2] R. Wang, Y. Qi, Z. Shen and Z. Wu, Huadong Huagong Xueyuan Xue, Vol. 4, 1982, p. 411.

[3] C. Leitenburg, D. Goi, A. Primavera, A. Trovarelli and G. Dolcetti, "Wet Oxidation of Acetic Acid Catalyzed by Doped Ceria,” Applied Catalysis B: Environmental, Vol. 11, No. 1, 1996, pp. L29-L35.

[4] J. E. Atwater, J. R. Akse, J. A. Mckinnis and J. O. Thompson, "Aqueous Phase Heterogeneous Catalytic Oxidation of Trichloroethylene," Applied Catalysis B: Environmental, Vol. 11, No. 1, 1996, pp. L11-L18. doi:10.1016/S0926-3373(96)00063-X

[5] R. Carlo, C. Federico, B. Silvia, P. Ombretta and B. Guido, "Catalytic wet oxidation of phenol over lanthanum strontium manganite," Applied Catalysis B: Environmental, Vol. 84, No. 3-4, 2008, p. 678.

[6] I. U. Castro, D. C. Sherrington, A. Fortuny, A. Fabregat, Stüber, F. Font and J. C. Bengoa, "Synthesis of Polymer-Supported Copper Complexes and Their Evaluation in Catalytic Phenol Oxidation," Catalysis Today, Vol. 157, No. 1-4, 2010, pp. 66-70. doi:10.1016/j.cattod.2010.02.006

[7] L. D. Souza, J. S. Subaie and R. Richards, “A Colloid 'Digesting' Route to Novel, Thermally Stable High Surface Area $\mathrm{ZrO}_{2}$ and $\mathrm{Pd} / \mathrm{ZrO}_{2}$ Catalytic Materials,” Journal of Colloid and Interface Science, Vol. 292, No. 2, 2005, pp. 476-485

[8] L. D. Souza, A. Suchopar, K. Zhu, D. Balyozova, M. Devadas and R. M. Richards, "Preparation of Thermally Stable High Surface Area Mesoporous Tetragonal $\mathrm{ZrO}_{2}$ and $\mathrm{Pt} / \mathrm{ZrO}_{2}$ : An Active Hydrogenation Catalyst," $\mathrm{Mi}$ croporous and Mesoporous Materials, Vol. 88, No. 1-3, 2006, pp. 22-30.

[9] J. M. Tatibouet, E. Guelou and J. Fournier, "Catalytic Oxidation of Phenol by Hydrogen Peroxide over a Pillared Clay Containing Iron. Active Species and pH Effect," Topics in Catalysis, Vol. 33, No. 1-4, 2005, pp. 225-232.

[10] A. E. Greenberg, L. S. Clesceri and A. D. Eaton, "Standard Methods-For the Examination of Water and Wastewater 18a Ed.," Part 5000, 6, APHA-AWWAWPCF, 1992.

[11] Q. Zhang and K. T. Chuang, “Alumina-Supported Noble Metal Catalysts for Destructive Oxidation of Organic Pollutants in Effluent from a Softwood Kraft Pulp Mill,” Industrial \& Engineering Chemistry Research, Vol. 37, No. 8, 1998, pp. 3343-3349. doi:10.1021/ie980111v

[12] C. Resini, F. Catania, S. Berardinelli, O. Paladino and G. Busca, "Catalytic Wet Oxidation of Phenol over Lanthanum Strontium Manganite,” Applied Catalysis B: Environmental, Vol. 84, No. 3-4, 2008, pp. 678-683. doi:10.1016/j.apcatb.2008.06.005

[13] M. Ilyas and M. Sadiq, "Kinetics of Heterogeneous Solvent-Free Liquid Phase Oxidation of Alcohol Using $\mathrm{ZrO}_{2}$ Catalyst with Molecular Oxygen," Chinese Journal of Chemistry, Vol. 26, No. 5, 2008, pp. 941-946. doi:10.1002/cjoc.200890172

[14] M. Ilyas and M. Sadiq, " $\mathrm{Pt} / \mathrm{ZrO}_{2}$ : An Efficient Catalyst for Aerobic Oxidation of Toluene in Aqueous Solution," Chinese Journal of Chemistry, Vol. 28, No. 11, 2010, p. 2216.

[15] D. V. Bavykin, A. A. Lapkin, S. T. Kolaczkowski and P. K. Plucinski, "Selective Oxidation of Alcohols in a Continuous Multifunctional Reactor: Ruthenium Oxide Catalysed Oxidation of Benzyl Alcohol," Applied Catalysis A: General, Vol. 288, No. 1-2, 2005, pp. 175-184. doi:10.1016/j.apcata.2005.04.042 